\title{
UPAH SIMPAN BARANG DALAM SKIM AR-RAHNU: SATU PENILAIAN SEMULA
}

\author{
Oleh: \\ Shamsiah Mohamad* \\ Safinar Salleh ${ }^{* *}$
}

\begin{abstract}
The objective of this paper is to evaluate whether the save custody fee imposed by institutions offering Islamic pawn broking facility in Malaysia is in accordance to the Islamic law. For the evaluation purpose, the basis of imposing of the fee i.e. wadi'ah yad damanah is analyzed to ensure that the basis is in line with the percepts of the al-rahn. The study found that the basis did not match the Islamic law. It also found that it is more accurate if the imposing of the fee is based on the expenditure incurred by the murtahin while the goods are in the murtahin's care due to the fact that the cost is borne by the rahin. The imposing of the fee can also be based on services given by the institutions for their customer.
\end{abstract}

* Prof. Madya, Jabatan Fiqh \& Usul, Akademi Pengajian Islam, Universiti Malaya, Kuala Lumpur.

** Pensyarah, Jabatan Undang-Undang Islam, Kuliyyah Undangundang Ahmad Ibrahim, Universiti Islam Antarabangsa Malaysia, Kuala Lumpur. 


\section{MUQADDIMAH}

Sistem gadaian Islam yang diperkenalkan di Malaysia sejak tahun 1992 merupakan alternatif kepada sistem gadaian konvensional. Dalam amalan gadaian konvensional, kedai-kedai pajak gadai berhak mengenakan faedah sebanyak 2 peratus sebulan atas pinjaman yang diberikan. ${ }^{1}$ Amalan tersebut amat bertentangan dengan prinsip muamalat Islam yang mengharamkan segala bentuk pengambilan untung ke atas pinjaman wang. ${ }^{2}$

Dalam usaha untuk membersihkan amalan gadaian daripada unsur riba, membantu golongan berpendapatan rendah serta memperkembangkan lagi sistem kewangan Islam di Malaysia, satu rancangan sistem pajak gadai Islam yang telah diperkenalkan. ${ }^{3}$ Apa yang menarik berhubung institusi-institusi gadaian Islam di Malaysia ialah mereka telah mengenakan caj upah simpan barang kepada penggadai. ${ }^{4}$ Upah ini dikenakan atas dasar barang gadaian

Peraturan-Peraturan Pemegang Pajak Gadai (Pindaan)1982.

2 Sebarang bentuk faedah yang disyaratkan termasuk dalam kategori riba yang diharamkan dalam Islam. Riba ini dinamakan sebagai riba jahiliyyah yang mana ia merujuk kepada pengambilan untung atas pinjaman wang yang diamalkan dalam masyarakat jahiliyyāh. Pengharaman amalan tersebut dinyatakan dalam ayat 130 surah Ali 'Imrān:

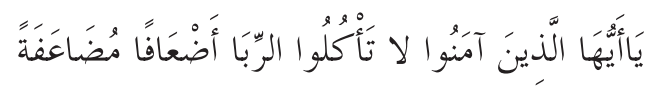

"Wahai orang-orang yang beriman! Janganlah kamu makan atau mengambil riba dengan berlipat ganda."

Lihat: Jawwād 'Alì (Dr.) (1971), al-Mufașșal fì Tārìkh al-'Arab Qabl al-Islām, j. 7. Beirut: Dār al-'Ilm lì al-Malāyīn, h. 426; Ibn Kathīr (t.t.), Tafsìr al-Qur'ān al-'Azīm, j. 1. Beirut: Dār al-Jayl, h. 381.

3 Tan Sri Jaffar Hussein telah menyarankan agar institusi-institusi di pinggir sistem perbankan seperti syarikat-syarikat pajak gadai diislamisasikan dalam usaha untuk mewujudkan sistem kewangan Islam yang lengkap dan canggih. Jaffar Hussein (Tan Sri Dato') (1990), "Sistem Kewangan Islam Dalam Dekad 1990-an” dalam Siri Syarahan Umum Universiti Sains Malaysia pada 9 Mac 1990 di Dewan Tuanku Syed Putra Universiti Sains Malaysia.

4 Hanya Muassasah Gadaian Islam Terengganu sahaja yang tidak mengenakan apa-apa bayaran ke atas penggadai. 
dikira sebagai wad'‘ ah sebagaimana jelas dinyatakan dalam pamplet skim ini oleh institusi-institusi berkenaan bahawa skim ini berdasarkan kepada prinsip al-qard al-hasan, al-rahn dan alwadi' 'ah. Persoalan yang timbul ialah, apakah asas pengambilan upah berkenaan betul-betul menepati syariat Islam atau sebaliknya? Justeru, artikel ini bertujuan untuk menilai semula kedudukan caj upah simpan yang diamalkan dalam Skim Ar-Rahnu (SAR) yang telah berjalan sekian lama.

\section{LATAR BELAKANG SKIM AR-RAHNU}

Sistem gadaian Islam di Malaysia mula diperkenalkan melalui penubuhan Muassasah Gadaian Islam Terengganu (MGIT) pada 23 Januari 1992. Pelaksanaan gadaian di MGIT adalah berteraskan kebajikan, di mana pinjaman yang diberikan tidak dikenakan sebarang caj. Peminjam disyaratkan agar mencagar barang gadaian yang terdiri daripada barang kemas yang diperbuat daripada emas dan berlian sebagai jaminan dan kadar pinjaman yang diberikan pula ialah sebanyak 75 peratus daripada nilai barang gadaian atau tidak melebihi RM 1500.00. Tempoh gadaian diberi selama tiga bulan dan boleh dilanjutkan selama tiga bulan lagi sebagai tambahan. Selepas tamat tempoh, pihak penghutang wajib membayar balik jumlah pokok yang telah dipinjamkan. ${ }^{5}$ Bagi mengambil semangat al-qard al-hasan, pihak penghutang boleh menunjukkan rasa terima kasihnya dengan memberikan sebarang hadiah atau sagu hati kepada MGIT. ${ }^{6}$

Seterusnya sistem ini diperkenalkan pula di negeri Kelantan. Permodalan Kelantan Berhad (PKB) yang merupakan anak syarikat Perbadanan Kemajuan Iktisad Negeri Kelantan (PKINK) telah membuka sebuah Kedai Ar-Rahnu pada Mac 1992. Berbeza dengan MGIT, penubuhan Kedai Ar-Rahnu adalah sebagai sebuah entiti perniagaan. Kedai Ar-Rahnu menawarkan pinjaman secara

Muassasah Gadaian Islam Terengganu, http://www.maidam.gov.my/ mgit_tatacara.php, 22 September 2008.

6 Shamsiah Mohamad (1994), "Perlaksanaan Gadaian Islam di Institusi-Institusi Gadaian Islam di Malaysia: Kajian Kes di Muassasah Gadaian Islam Terengganu" (Disertasi Sarjana, Fakulti Syariah, Akademi Pengajian Islam, Universiti Malaya), h. 128-156. 
al-qard al-hasan di samping mengenakan caj upah simpan (ujrah) barang yang dicagarkan. Kadar upah yang dikenakan adalah lebih rendah daripada kadar faedah semasa dan bergantung kepada nilai barang gadaian. ${ }^{7}$ Kini terdapat lima buah cawangan Kedai ArRahnu di seluruh negeri Kelantan. ${ }^{8}$

Pada 27 Oktober 1993 pihak Yayasan Pembangunan Ekonomi Islam Malaysia (YPEIM) bersama Bank Negara Malaysia (BNM) telah memperkenalkan SAR melalui Bank Kerjasama Rakyat Malaysia (Bank Rakyat). Dalam skim ini YPEIM bertindak sebagai penyelaras dan pelabur utama manakala BNM bertindak sebagai urusetia dan penasihat. Operasi SAR yang dilaksanakan di Bank Rakyat sama seperti kaedah yang dilaksanakan di Kedai Ar-Rahnu di mana para penggadai dikenakan caj upah simpan barang gadaian. Pihak YPEIM kemudiannya melebarkan lagi skim ini melalui kerjasamanya dengan Bank Islam Malaysia Berhad (BIMB) pada November 1997. ${ }^{9}$ Kaedah pelaksanaannya adalah sama seperti yang dilaksanakan di Bank Rakyat. Pada 15 September 2002, pihak YPEIM sendiri menawarkan skim ini melalui kaunter Koperasi YPEIM Berhad. Sehingga tahun 2002 skim ini beroperasi melalui 136 buah kaunter dengan jumlah pembiayaan sebanyak RM738.7 juta dan telah memberi manfaat kepada 817,910 orang pelanggan. ${ }^{10}$

Kejayaan skim ini telah menarik minat Bank Pertanian Malaysia (BPM). Skim ini mula ditawarkan pada 2 September 2002 melalui dua cawangannya iaitu Tanjung Karang dan Pasir

7 Lihat Aziz Nawi (2001), "Penerimaan Ar-Rahnu Dalam Masyarakat: Pengalaman Permodalan Kelantan Berhad" dan Syed Mohd. Ghazali Wafa (2001), "Pelaksanaan Perkhidmatan al-Rahn di Malaysia " (Kertas Kerja Seminar Kefahaman Mengenai Konsep dan Aplikasi Sistem Ar-Rahnu di Institut Kefahaman Islam Malaysia, 12-13 November 2001).

8 Gemaputera.http://www.gemaputera.org.my/preview/jan2002. asp\#topik4, 7 Jun 2002.

9 Mokhtar Abdul Razak (2002), "Skim Ar-Rahnu: Suatu Produk Pembangunan Sosio-Ekonomi” (Kertas Kerja Konvensyen ArRahnu Serantau, Yayasan Pembangunan Ekonomi Islam Malaysia, Kuala Lumpur, 9-10 April 2002), h. 3.

10 Ibid. 
Mas. Langkah ini diambil setelah menyedari bahawa kebanyakan pelanggan skim ini adalah terdiri daripada para petani, nelayan dan peniaga kecil yang mana kebanyakan mereka merupakan pemegang akaun BPM. Sehingga Mac 2005, terdapat 12 cawangan BPM yang telah menawarkan skim ini. ${ }^{11}$ Kejayaan skim ini juga telah berjaya menarik minat bank konvensional untuk turut serta. EON Bank Group melalui kaunter Skim Perbankan Islam (SPI) telah menawarkan SAR di 10 cawangannya setakat ini. ${ }^{12}$

Di samping itu, terdapat institusi-institusi lain yang turut menawarkan skim tersebut seperti koperasi-koperasi dan kerajaan negeri. ${ }^{13}$ Sebagai contoh, pada Januari 1997 Kerajaan Negeri Perlis telah menubuhkan Pajak Gadai Islam (PGI). Selain koperasi Bank Rakyat, beberapa koperasi lain seperti Koperasi Pengguna Pahang Berhad, Koperasi Gabungan Pekebun Kecil Perak Berhad, Koperasi Badan Berkanun (KOKANUN) di Terengganu dan Koperasi Jamaiyah Orang-Orang Melayu Perlis Berhad (KOJAM) juga menawarkan skim ini. Pihak Jabatan Pembangunan Koperasi (JPK) telah meluluskan skim ini sebagai salah satu projek yang boleh diceburi oleh pihak koperasi dan berhak untuk memohon pembiayaan dari Tabung Pusingan Modal. Kesemua institusi terbabit menggunakan kaedah yang sama sebagaimana yang dilaksanakan di Bank Rakyat.

Kini terdapat dua bentuk operasi gadaian Islam yang dijalankan di seluruh Malaysia. Pertama, institusi gadaian yang menjalankan aktiviti berteraskan kebajikan semata-mata yang memberi pinjaman tanpa tambahan faedah dan caj upah simpan barang seperti yang dilaksanakan di MGIT. Kedua, institusi yang menjalankan perniagaan dengan memberi kemudahan pinjaman dengan mengenakan caj upah simpan.

\footnotetext{
11 BPM, http://www.bpm.com.my/, 7 Mac 2005.

12 http://www.eonbank.com.my/Islamic_Banking/Financing/ar-rahnu_ pawnbroking-i.htm, 19 April 2005.

13 Abdul Ghafar Haji Ismail (2002), op.cit., h. 6.
} 


\section{PRINSIP-PRINSIP SYARIAH DALAM SKIM AR-RAHNU}

SAR ditubuhkan atas dasar Fardhu Kifayah dan bukan atas dasar keuntungan semata-mata oleh pelaksananya. Antara tujuan utamanya ialah untuk menghapuskan riba atau hasil bunga (faedah) dan gharar yang terdapat dalam pajak gadai secara konvensional. Skim ini memberikan kemudahan alternatif kepada kemudahan pinjaman yang sedia ada di samping memberi pilihan kepada peminjam untuk menuruti kehendak dan hukum Syariah. ${ }^{14}$

Sebagai saluran pinjaman bebas riba, skim ini menggabungkan beberapa konsep fiqh seperti al-qard al-hasan, al-rahn dan alwadi' 'ah yad damānah. ${ }^{15}$ Berdasarkan konsep al-qard al-hasan, skim ini beroperasi dengan memberi pinjaman ihsan tanpa sebarang faedah. Sebagai saluran pinjaman mudah, skim ini dapat membantu golongan sasaran yang terdiri daripada golongan berpendapatan rendah serta para peniaga kecil. Dalam Islam, kontrak al-qard sememangnya diperkenalkan sebagai sarana kebajikan bagi membantu golongan yang mengalami kesempitan wang. Kepentingannya dapat difahami berdasarkan galakan dan penghargaan yang diberikankan oleh Rasulullah SAW. kepada pihak-pihak yang bermurah hati memberikan pinjaman kepada orang lain yang memerlukan sebagaimana yang dinyatakan dalam hadith-hadith berikut:

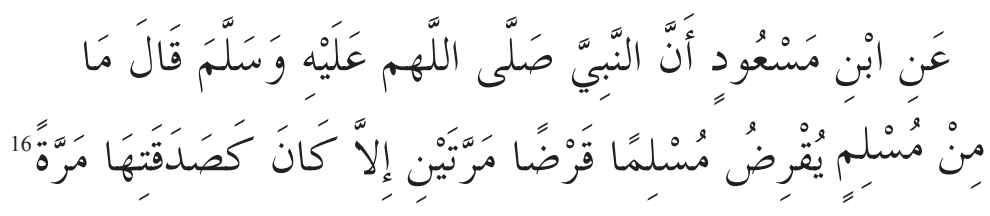

14 Pelancar Online, "Skim Pajak Gadai Islam Ar-Rahnu:Konsep Dan Perlaksanaannya", http://www.angkasa.coop/pelancar/Arkib/Jan05/ januari5.htm, 20 April 2005

15 Ibid.

16 Muhammad b. Yazid al-Qazwini b. Majah (t.t.), Sunan Ibn Mājah. Kitāb al-Sadaqāt, Bab al-Qarḍ, no. hadith 2430. 
Maksudnya:

"Daripada Ibn Mas'ud bahawasanya Rasulullah SAW. telah bersabda: Barangsiapa yang memberi pinjaman kepada seorang muslim sebanyak dua kali maka ia adalah seumpama dia memberi sedekah satu kali."

(Riwayat Ibn Mājah)



Maksudnya:

"Anas b. Malik telah berkata, Rasulullah SAW telah bersabda bahawa pada malam Isra' aku melihat tulisan di pintu syurga yang menyatakan bahawa pahala memberi sedekah sebanyak sepuluh kali ganda manakala pahala memberi pinjaman pula sebanyak lapan belas kali ganda. Aku pun bertanya kepada Jibril A.S.: Wahai Jibril! Kenapa pahala memberi pinjaman lebih banyak daripada pahala memberi sedekah? Jibril menjawab, orang yang meminta kadang kala meminta padahal dia sudah mempunyai sedangkan orang yang meminjam tidak akan meminjam melainkan dia memang memerlukan."

(Riwayat Ibn Mājah)

Melalui SAR, para peminjam boleh mendapatkan pinjaman dengan mudah dan mereka hanya perlu membayar jumlah pinjaman pokok sahaja dalam tempoh yang telah ditetapkan. Walau bagaimanapun, peminjam dikehendaki mencagar barang kemas kepada pihak bank atau pajak gadai sebagai jaminan kepada hutang tersebut. Berdasarkan prinsip al-rahn, pihak pajak gadai atau bank berhak

17 Ibid., no. hadith 2431. 
memegang barang gadaian sehingga semua hutang dilunaskan. ${ }^{18}$ Sekiranya hutang tersebut tidak dijelaskan, maka barang gadaian itu tadi boleh digunakan untuk menjelaskan hutang tersebut. Barang gadaian akan dijual dan hasil jualan itu akan digunakan untuk membayar hutang manakala bakinya dipulangkan kepada penggadai. ${ }^{19}$ Bagi mencapai matlamat jaminan hutang tersebut, pihak bank dan pajak gadai telah menghadkan penerimaan barang gadaian kepada barangan yang diperbuat daripada emas sahaja. ${ }^{20}$ Dalam hal ini, walaupun skim ini dinamakan sebagai SAR tetapi kontrak gadaian atau al-rahn bukanlah kontrak teras dalam skim ini sebaliknya ia hanyalah kontrak sokongan sahaja. Walau bagaimanapun, kedudukan kontrak ini sebagai sokongan kepada kontrak al-qard adalah menepati saranan syarak yang menggalakkan supaya urusan muamalat secara hutang direkodkan atau dibuat penyaksian ataupun dijamin dengan barang gadaian sebagaimana yang dijelaskan dalam firmanNya:

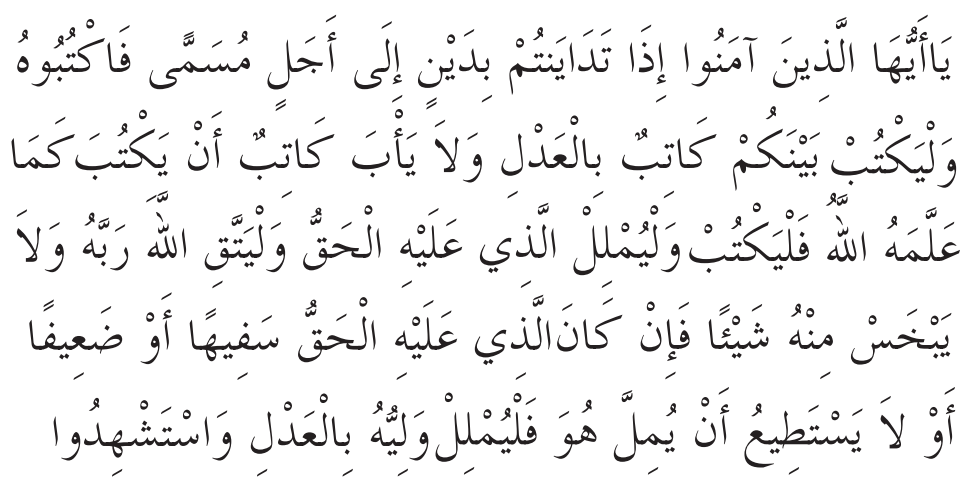

18 al-Zayla'‘̄i (t.t.), Tabyīn al-Haqā'iq, j. 6, c. 2. Kaherah: Dār al-Kitāb al-Islāmì, h.78.

19 Muwaffiq al-Dīn b. Qudāmah (1994), al-Mughnī wa al-Syarh alKabìr, j. 4. Beirut: Dār al-Fikr, h. 488.

20 Bank Rakyat, http://www.bankrakyat.com.my, Bank Pertanian Malaysia, http://www.bpm.com.my/, 25 Oktober 2003; Ar-Rahnu Pawnbroking-i, EON Bank Group, http://www.eonbank.com.my/ Islamic_Banking/Financing/ar-rahnu_pawnbroking-i.htm, 4.4.2005; Muassasah Gadaian Islam Terengganu, http://www.maidam.gov.my/ mgit_tatacara.php, 22 September 2008. 


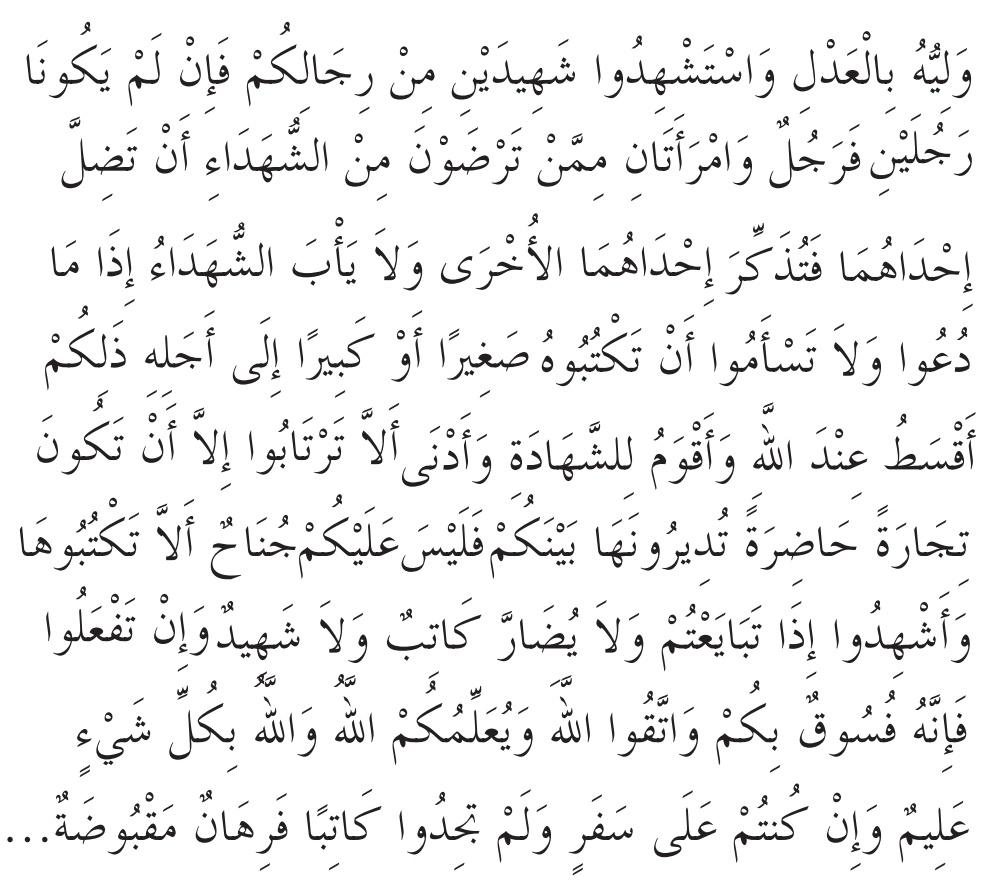

Maksudnya:

"Wahai orang-orang yang beriman! Apabila kamu menjalankan sesuatu urusan dengan hutang piutang yang diberi tempoh hingga ke suatu masa yang tertentu maka hendaklah kamu menulis (hutang dan masa bayarannya) itu dan hendaklah seorang penulis di antara kamu menulisnya dengan adil (benar) dan janganlah seseorang penulis enggan menulis sebagaimana Allah telah mengajarkannya. Oleh itu, hendaklah ia menulis dan hendaklah orang yang berhutang itu merencanakan (isi surat hutang itu dengan jelas). Dan hendaklah ia bertaqwa kepada Allah Tuhannya, dan janganlah ia mengurangkan sesuatu pun dari hutang itu. Kemudian jika orang yang berhutang itu bodoh atau lemah atau ia sendiri tidak dapat hendak merencanakan (isi itu), maka hendaklah direncanakan oleh walinya dengan adil. Dan hendaklah kamu mengadakan dua orang saksi lelaki dari kalangan kamu. Kemudian kalau tidak ada saksi dua orang lelaki, maka bolehlah, 
seorang lelaki dan dua orang perempuan dari orangorang yang kamu setujui menjadi saksi, supaya jika yang seorang lupa dari saksi-saksi perempuan yang berdua itu maka dapat diingatkan oleh yang seorang lagi. Dan jangan saksi-saksi itu enggan apabila mereka dipanggil menjadi saksi. Dan janganlah kamu jemu menulis perkara hutang yang bertempoh masanya itu, sama ada kecil atau besar jumlahnya. Yang demikian itu, lebih adil di sisi Allah dan lebih membetulkan (menguatkan) keterangan saksi, dan juga lebih hampir kepada tidak menimbulkan keraguan kamu. Kecuali perkara itu mengenai perniagaan tunai yang kamu jalankan sesama sendiri, maka tiadalah salah jika kamu tidak menulisnya. Dan adakanlah saksi apabila kamu berjual-beli. Danjanganlah mana-mana jurutulis dan saksi itu disusahkan. Dan kalau kamu melakukan (apa yang dilarang itu), maka sesungguhnya yang demikian adalah perbuatan fasik (derhaka) yang ada pada kamu. Oleh itu hendaklah kamu bertaqwa kepada Allah; dan (ingatlah), Allah (dengan keterangan ini) mengajar kamu, dan Allah sentiasa Mengetahui akan tiap-tiap sesuatu." "Jika kamu dalam perjalanan (dan bermuamalat tidak secara tunai) sedang kamu tidak memperoleh seorang penulis maka hendaklah ada barang tanggungan yang dipegang (oleh yang berpiutang) ..."

Surah al-Baqarah (2):282-283

Sementara prinsip al-wadī'ah yad damānah pula ialah akad di antara tuan punya barang dengan pihak yang menyimpan barang gadaian tersebut. Atas dasar al-wadi' $a h$ inilah, skim ini akan mengenakan bayaran upah simpan selamat (safe custody fee) ke atas barang gadaian tadi. Secara ringkasnya, skim ini tidak akan mengenakan faedah kepada pinjaman tetapi hanya mengambil upah untuk menyimpan dengan selamat ke atas barang gadaian.

\section{ASAS PENGAMBILAN UPAH SIMPAN}

Sebagaimana yang telah dijelaskan di atas, SAR ini berasaskan 3 prinsip syariah yang utama iaitu al-qard al-hasan, al-rahn dan alwad' 'ah yad damānah. Prinsip pertama merujuk kepada pinjaman 
wang yang diberi kepada pelanggan/penggadai oleh institusiinstitusi gadaian Islam. Prinsip kedua pula merujuk kepada cagaran yang diberi oleh pelanggan/penggadai kepada institusi berkenaan. Manakala prinsip ketiga merujuk kepada upah simpan barang yang dikenakan ke atas pelanggan/penggadai. ${ }^{21}$

Daripada kenyataan di atas, jelas sekali bahawa upah simpan yang dikenakan ke atas penggadai adalah berasaskan prinsip alwadi' 'ah yad damānah. Ini bermakna pemegang gadai menyimpan barang gadaian dengan jaminan keselamatan dan mengenakan bayaran upah simpan mengikut kadar yang tertentu. Sekiranya berlaku kehilangan atau kerosakan semasa dalam simpanan, pihak pemegang gadai bertanggungjawab mengganti atau membayar gantirugi kepada pelanggan. Persoalannya, apakah barang gadaian yang berada dalam jagaan pemegang gadai disifatkan sebagai wadi'ah sehingga membolehkan pemegang gadai mengenakan caj upah simpan barang?

Daripada penulisan para fuqaha', dapat difahami bahawa apabila penggadai menggadai hartanya kepada pemegang gadai, maka adalah menjadi hak pemegang gadai untuk meletakkan barang gadaian di bawah kawalannya. Hak tersebut diperolehi bagi menjamin bayaran balik hutangnya/pinjamannya daripada penggadai. Dengan kata lain, apabila sempurnanya akad al-rahn, adalah menjadi kewajipannya menyerahkan barang gadaian kepada pemegang gadai sebagaimana dapat difahami daripada firman Allah:

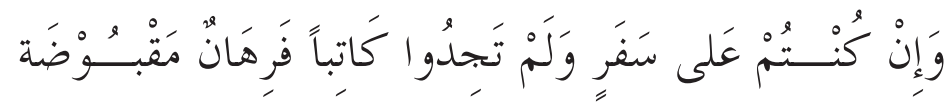

Maksudnya:

"Dan jika kamu dalam perjalanan (dan bermuamalat secara tidak tunai) sedang kamu tidak memperoleh seorang penulis maka hendaklah ada barang tanggungan yang dipegang (oleh orang yang memberi hutang)..."

Surah al-Baqarah (2): 283

21 http://www.bankrakyat.com.my, Perkara 1.1 GPO Skim ar-Rahnu BPM. 
Berdasarkan ayat di atas, para fuqaha' sepakat mengatakan bahawa serahan barang gadaian merupakan syarat penting dalam akad al-rahn walaupun mereka berbeza pendapat ${ }^{22}$ dari segi penentuan sama ada syarat tersebut syarat $l u z \bar{u} m^{23}$ atau syarat tamām. ${ }^{24}$ Ini bermakna, tanpa penyerahan barang gadaian, ia tidak sah kerana objektif utama akad al-rahn iaitu sebagai jaminan hutang tidak tercapai.

Ini amat berlawanan dengan akad wadi' $a h$ di mana $m \bar{u} d i$ ‘ (yang menjaga wad'‘ $a h$ ) menjaganya atas permintaan pemilik barang. Malah pemilik barang telah meletakkan hartanya di bawah pengawasan $m \bar{u} d i^{\prime}$ bukan dengan niat sebagai cagaran atau jaminan kepada hutang tetapi semata-mata atas dasar menjaga barang tersebut. Abū Ḥanifah dan Abū Yūsuf sendiri membezakan antara kontrak al-rahn dan kontrak al-wad' ‘ $a h$ dalam perbincangan mereka mengenai lafaz gadaian. ${ }^{25}$

22 Jumhur fuqaha' yang terdiri daripada Ḥanafī, Syāfíc $\bar{i}$ dan Ḥanbali menyifatkan penyerahan barang gadaian sebagai syarat luzūm. Fuqaha' Mālikì pula menyifatkannya sebagai syarat tamām sahaja kerana akad al-rahn menjadi lazim (kedua-dua pihak terikat dengan kontrak) sebaik sahaja lafaz ijāb dan qabūl sempurna dilakukan. Lihat: Ibn Rushd (1988), Bidāyah al-Mujtahid, j. 2. Beirūt: Dār al-Qalam, h. 277; Muhammad b. Husayn b. 'Alì al-Ṭūrì al-Qādirī (1977), Takmilah al-Baḥr al-Rā'iq, j. 8. Beirūt: Dār al-Kutub al'Ilmiyyah, h. 429.

23 Apabila penyerahan barang gadaian disifatkan sebagai syarat luzum, ini bermakna pihak penggadai berhak membatalkan akad al-rahn pada bila-bila masa walaupun tanpa persetujuan pemegang gadai selagi mana barang gadaian belum diserahkan kepada pemegang gadai atau pihak ketiga yang dilantik oleh mereka. Apabila penyerahan telah berlaku, penggadai hanya boleh membatalkan akad al-rahn jika dipersetujui oleh pemegang gadai.

24 Apabila penyerahan barang gadaian disifatkan sebagai syarat tamam, maknanya akad gadaian tidak dianggap sempurna selagi mana penyerahan tidak dilakukan.

25 Lihat: Maḥmūd al-Awzajandī (1991), Fatāwà al-Qādịkhān, c.2, j.3. Beirūt:Dār al-Fikr, h.593. 
Ini bermakna, kedudukan barang gadaian di tangan pemegang gadai bukanlah terhasil daripada kontrak al-wadi' $a h$, tetapi ia merupakan tuntutan akad al-rahn itu sendiri. Oleh itu, menjadikan prinsip al-wadi' ah yad damānah sebagai asas bagi membolehkan institrusi-institusi yang menawarkan kemudahan gadaian Islam di Malaysia adalah tidak menepati hukum syarak. Oleh itu, amat wajar isu ini diambil berat oleh pihak yang berkenaan agar apa yang dilakukan benar-benar selaras dengan ajaran Islam.

\section{ALTERNATIF KEPADA PRINSIP $W A D I ' A H Y A D$ DAM $\bar{A} \boldsymbol{N} \boldsymbol{A} H$}

Satu perkara yang perlu dilihat dalam penawaran sistem pajak gadai Islam ialah aspek nafkah atau perbelanjaan yang melibatkan barang gadaian. Dalam Islam, pemilik barang bertanggungjawab sepenuhnya ke atas segala perbelanjaan yang melibatkan barang hak miliknya. Ini bermakna penggadai juga bertanggungjawab ke atas perbelanjaan yang melibatkan barang gadaian kerana barang gadaian merupakan hak miliknya meskipun ia berada dalam kawalan pemegang gadai. Ini dapat difahami daripada hadith Rasulullah SAW:



Maksudnya:

"Daripada Abu Hurairah r.a., sabda Rasulullah SAW: (Hak milik) barang gadaian tidak akan hilang (daripada pemiliknya). Semua keuntungan (yang terhasil daripadanya) menjadi miliknya dan segala kerugian juga ditanggung olehnya."

(Riwayat Dāruquṭīi)

26 Al-Dāraquțīi (1993), Sunan al- Dāraquṭnì, Kitāb al-Buyū', no. hadith 126. 
Al-Ṣan 'āni menjelaskan bahawa perbelanjaan yang melibatkan barang gadaian termasuk dalam erti kata kerugian yang perlu ditanggung oleh pihak penggadai. ${ }^{27}$ Oleh itu, jelas bahawa penggadai yang menjadi pemilik barang gadaian bertanggungjawab mengeluarkan perbelanjaan untuk tujuan pengurusan dan penjagaan barang gadaian. Walaupun fuqaha' Hanafĩ berpendapat pemegang gadai bertanggung jawab menanggung perbelanjaan untuk penjagaan barang gadaian seperti kos tempat simpanan dan upah pengawal, tetapi pada pandangan penulis, adalah tidak sepatutnya kos tersebut ditanggung oleh pemegang gadai kerana ia akan memudaratkannya apatah lagi dalam realiti hari ini di mana pemegang gadai adalah sebuah institusi dan bukannya individu. Ini kerana institusi ini memberi khidmat kepada ribuan orang dan ini menuntut pihak berkenaan agar menyediakan tempat dan kemudahan yang sewajarnya di samping mengambil pekerja bagi menguruskan kemudahan yang mereka sediakan kepada orang ramai. Dengan kata lain pihak institusi menanggung kos pengurusan yang agak besar berbanding individu yang mungkin hanya bersedia memberi khidmat kepada seorang atau dua orang sahaja; dan ini tidak memerlukannya untuk menyewa premis tersendiri untuk urusan berkenaan malah barang gadaian boleh disimpan di rumahnya. Ringkasnya, jika kos penjagaan tersebut ditanggung oleh pemegang gadaian maka ini bermakna dia terpaksa menanggung kerugian sedangkan dia bukan pemilik kepada barang gadaian. Oleh itu, pendapat yang mengatakan segala perbelanjaan ditanggung oleh penggadai adalah lebih realistik dan bertepatan dengan hadith di atas malah amat bersesuaian dengan matlamat gadaian iaitu untuk memberi satu kelapangan atau ketenangan kepada pemiutang. ${ }^{28}$

27 Al-Ṣan'ānì (1986), Subul al-Salām, j.3, c.2. Beirūt: Dār al-Kitab al'Arabi, h.103.

28 Pandangan ini didukung oleh fuqaha Māliki, Syāfi' ${ }^{\prime} \bar{i}$ dan Hanbali. Lihat: al-Khurasyì (1997), Hâasyiyah al-Khurasyì, j.6. Beirūt: Dār alKutub al-'Ilmiyyah, h. 162; al-Muțī‘i (t.t.), Kitāb al-Majmū' Syarh al-Muhadhdhab, j. 12, c. 2. Jeddah: Maktabah al-Irsyād, h. 376; Muwaffiq al-Din b. Qudāmah (1994), al-Mughnì, j. 4. Beirūt: Dār al-Fikr, 474. 
Sekiranya penggadai tidak melaksanakan tanggungjawab tersebut disebabkan keengganannya atau dia menghilangkan diri, maka pemegang gadai boleh mengeluarkan perbelanjaan untuk barang gadaian berkenaan. Ini bertujuan memastikan barang gadaian berada dalam keadaan selamat dan baik supaya ia terus boleh berfungsi sebagai jaminan hutang. Dalam keadaan ini, pemegang gadai berhak menuntut kembali segala perbelanjaan tersebut daripada pihak penggadai kerana apa yang telah dibelanjakan olehnya dikira hutang yang wajib dibayar oleh penggadai.

Merujuk kepada realiti hari ini sebagaimana yang berlaku di institusi-institusi pajak gadai Islam, adalah menjadi tanggungjawab penggadai untuk menanggung kos penjagaan barang gadaian. Oleh itu, adalah wajar bagi pihak pemegang gadai mengenakan bayaran tertentu ke atas penggadai atas dasar kos penjagaan barang gadaian.

Bertitik tolak daripada isu di atas juga, timbul persoalan apakah wajar pihak berkenaan mengambil keuntungan melalui bayaran berkenaan. Bagi menghurai persoalan ini, penelitian kepada hadith Rasulullah SAW. berhubung mengambil manfaat daripada barang gadaian perlu dibuat. Sabda Rasulullah SAW: ${ }^{29}$

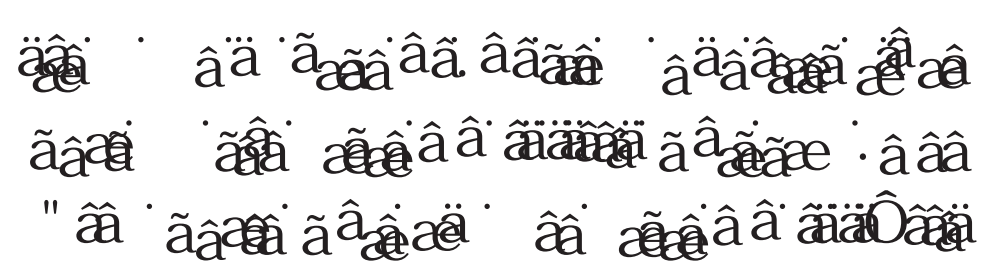

Maksudnya:

"Daripada Abu Hurairah r.a. bahawa Rasulullah SAW telah bersabda: Binatang ternakan yang digadai boleh ditunggangi dan diperah susunya (sekadar) nafkah yang telah dibelanjakan untuknya. Dan orang yang menunggang dan memerah susunya mesti memberi nafkah ke atas binatang tersebut."

(Riwayat Bukhārī)

29 Al-Bukhārì (t.t.), Sahịh al-Bukhārī, Kitāb al-Rahn, Bab al-Rahn Markūb wa Maḥlūb, no. hadith 2512. 
Para ahli hadith menyatakan bahawa hadith tersebut ditujukan kepada pemegang gadai. Ini kerana keharusan menggunakan barang gadaian itu diberikan atas dasar perbelanjaan yang telah dikeluarkan. Sekiranya ia merujuk kepada penggadai, maka tidak perlu dikaitkan dengan perbelanjaan kerana sebagai pemilik dia berhak menggunakan barang hak miliknya. ${ }^{30}$

Dalam menghuraikan hadith di atas, al- 'Asqalāni telah menukil satu riwayat daripada Hammad b. Salāmah yang menyatakan: ${ }^{31}$

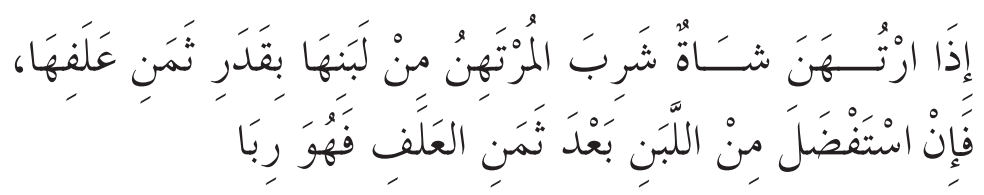

Maksudnya:

"Apabila seekor biri-biri itu telah digadai, pemegang gadai boleh meminum susunya sekadar perbelanjaan makan minum yang telah dikeluarkan untuk binatang tersebut. Sekiranya susu yang diambil itu lebih daripada kadar yang telah dibelanjakan maka ia adalah riba."

Jelas daripada huraian di atas bahawa, kos penjagaan yang perlu dibayar balik oleh penggadai tidak melebihi kos sebenar yang telah dikeluarkan oleh pemegang gadai. Ini disebabkan apa yang dituntut daripada penggadai adalah hutang kerana pemegang gadai mendahulukan wangnya bagi perbelanjaan barang gadaian berkenaan. Oleh itu amat tidak wajar bagi pemegang gadai untuk menuntut lebih daripada perbelanjaan yang telah dikeluarkannya.

Justeru, pihak pemegang gadai sebenarnya boleh mengenakan bayaran tertentu kepada penggadai berasaskan kepada tuntutan ke atas segala perbelanjaan yang dikeluarkan olehnya. Bayaran yang dikenakan ke atas penggadai sebenarnya bukan sebagai upah

30 Lihat: al-'Asqalānī (t.t.), Fath al-Bārìi, j. 5. Beirūt: Dār al-Ma'rifah, h.443; al-Syawkāni (1993), Nayl al-Awtār , j. 5. Kaherah: Maktabah al-Kulliyyah al-Azhariyyah, h. 279; Abādī, 'Awn al-Ma'būd Syarh Sunan Abī Dawūd, j.9. Beirūt:Dār al-Kutub al-'Ilmiyyah, hh. 320321.

31 Al-‘Asqalāni (t.t.), op.cit., h. 443. 
penjagaan atau bukan berasaskan konsep wadi' $a h$ sebagaimana yang dilaksanakan hari ini.

Sebenarnya penentuan asas kepada pengenaan bayaran tersebut mempunyai kesan yang besar dari aspek hukum. Jika dikatakan bayaran yang dibuat oleh pemegang gadai merupakan upah simpan barang iaitu berasaskan kepada konsep wadi'ah, maka ia sudah lari dari hakikat al-rahn itu sendiri. Ini kerana dalam Islam, berasaskan kepada akad al-rahn, pemegang gadai sememangnya diberi hak untuk meletakkan barang gadaian dalam pengawasannya. Hak ini diberi demi menjaga kepentingannya iaitu sebagai jaminan bayaran balik hutangnya. Perletakan barang gadaian di bawah jagaan pemegang gadai sebenarnya bukan atas dasar akad wad' 'ah tetapi berasaskan hak yang diberi hasil dari akad al-rahn. Sedangkan dalam akad wad'‘ $a h$, pihak yang menjaga barang wadi'ah sememangnya bertanggungjawab melakukan tugasan tersebut apabila selesai akad berkenaan kerana itu merupakan matlamat utama akad wadi' $a h$ dilakukan.

Sebaliknya, jika asas kepada pengenaan bayaran tersebut ialah tuntutan bayaran balik kepada perbelanjaan (atau dalam istilah fiqh disebut nafkah) yang dikeluarkan oleh pemegang gadai semasa barang tersebut dalam jagaannya, maka ia merupakan asas yang tidak berlawanan dengan konsep al-rahn. Ini kerana, pemilik kepada barang gadaian ialah penggadai. Oleh itu kos penjagaan barang gadaian sebenarnya menjadi tanggungjawab pemilik.

Apabila kita merujuk kepada realiti yang berlaku dalam amalan gadaian Islam di Malaysia hari ini, sememangnya barang gadaian berada dalam pengawasan pemegang gadai. Persoalan yang timbul, jika segala kos penjagaan ditanggung oleh pemilik iaitu penggadai, maka bagaimana caranya untuk menguruskan perbelanjaan tersebut. Apakah pemegang gadai perlu dapatkan wang pendahuluan atau menuntut segala perbelanjaan pada tarikh tebus iaitu apabila tempoh hutang tamat? Berasaskan kepada perbincangan di atas, penulis mendapati ada ruang bagi pemegang gadai untuk mengenakan bayaran kepada penggadai bagi menampung perbelanjaan penjagaan barang gadaian. Cuma persoalan yang mungkin timbul ialah apakah pemegang gadai boleh mengenakan bayaran sesuka hati malah mengambil keuntungan melalui bayaran tersebut? Pada pandangan penulis, apabila kita 
merujuk kepada hadis yang diriwayatkan oleh Hammad bin Salamah di atas, jelas bahawa bayaran yang boleh dituntut oleh pemegang gadai ialah sekadar apa yang telah dibelanjakan. Ini bermaksud, pemegang gadai tidak boleh menjadikan bayaran tersebut sebagai laluan untuk mengaut keuntungan.

Walau bagaimanapun, dalam proses menentukan kos perbelanjaan yang terlibat dalam penjagaan barang gadaian, pihak pemegang gadai boleh menetapkan formula yang munasabah dan dalam hal ini pihak pemegang gadai boleh merujuk kepada pakar yang berkaitan. Apa yang penting, formula mampu dijadikan asas dalam pengiraan perbelanjaan yang terlibat. Penulis berpandangan, dalam menentukan kos perbelanjaan bukanlah semestinya mesti seratus peratus tepat seperti yang sebenarnya dibelanjakan. Ini kerana dalam hadis yang disebut di atas, penggadai dibenarkan meminum susu kambing sekadar nafkah yang telah dikeluarkan. Persoalannya, bagaimana hendak dipastikan jumlah susu yang diambil benar-benar menepati jumlah sebenar perbelanjaan yang telah dikeluarkan? Oleh itu, apa yang dapat difahami daripada hadis tersebut, pemegang gadai disaran meminum susu sekadar yang munasabah telah mencukupi untuk menggantikan segala perbelanjaaan yang telah dikeluarkan. Ini bermakna, kadar bayaran yang ditetapkan bagi menampung perbelanjaan penjagaan barang gadaian boleh ditentukan secara anggaran tetapi ia hendaklah munasabah. Anggaran ini boleh dibuat menggunakan formula tertentu.

Merujuk kepada formula penentuan upah simpan barang yang ditetapkan oleh pihak yang menawarkan skim al-Rahnu di Malaysia seperti Bank Rakyat dan Kedai Ar-Rahnu di Kelantan, penulis berpandangan ia perlu disemak semula dan dirujuk kepada pakar dalam bidang berkenaan. Sekiranya formula sedia ada adalah munasabah bagi menentukan anggaran kos perbelanjaan penjagaan barang gadaian berkenaan, maka formula tersebut boleh terus diterimapakai.

Selain daripada menjadikan tuntutan bayaran balik nafkah (kos perbelanjaan) penjagaan barang gadaian sebagai asas pengambilan bayaran/upah, pemegang gadai (pemberi pinjam) boleh mengenakan bayaran/caj perkhidmatan ke atas penggadai (peminjam). Dalam masalah pengenaan caj perkhidmatan ini, 
para ulama telah membincangkannya dalam Persidangan Ketiga Perhimpunan Fiqh Islam, yang diadakan di Amman, Jordan pada 8-13 Safar 1407H bersamaan dengan 6-11 Oktober 1986. Pendapat majoriti ulama cenderung mengatakan bahawa hukumnya adalah harus (diperbolehkan) dengan peringatan bahawa adalah lebih baik tidak melaksanakannya. Keharusan tersebut diberi kerana jika khidmat pinjaman itu diberi oleh institusi, ia akan melibatkan kos untuk menyelenggarakan beberapa urusan akad, merekod data dan gaji para pekerja yang terlibat.

Berdasarkan kepada apa yang dibincangkan sebelum ini, instistusi-institusi yang menawarkan Skim Ar-Rahnu sepatutnya mengenakan bayaran upah ke atas pelanggannya atas 2 asas iaitu pertamanya tuntutan balik nafkah penjagaan barang gadaian yang telah dikeluarkannya dan keduanya khidmat pinjaman yang melibatkan kos-kos tertentu seperti yang disebut sebelum ini. Dengan lain perkataan, terdapat dua asas yang tidak bertentangan dengan hukum-hakam al-rahn yang membolehkan bayaran upah diambil oleh institusi-institusi gadaian Islam.

\section{KESIMPULAN}

Daripada perbincangan di atas dapat disimpulkan bahawa upah simpan barang dalam skim Ar-Rahnu di Malaysia yang diasaskan kepada konsep wad' 'ah yad damānah adalah bertentangan dengan konsep dan hakikat al-rahn yang telah diperkatakan di atas. Apatah lagi sekiranya bayaran tersebut dijadikan jalan untuk meraih keuntungan daripada transaksi pajak gadai berkenaan. Jelas dalam Islam bahawa, gadaian hanya berfungsi sebagai jaminan kepada bayaran balik hutang berkenaan dan bukannya saluran yang dibenarkan syarak untuk mencari keuntungan. Akad al-rahn sebagaimana diketahui adalah akad yang hanya boleh dilakukan bersama-sama dengan akad hutang (pinjaman atau mana-mana akad yang berbentuk hutang seperti jual beli secara hutang). Dalam transaksi hutang, pihak yang berhutang hanya wajib membayar balik jumlah hutang yang diterimanya sahaja dan adalah haram pihak pemiutang menuntut bayaran lebih. 
